\title{
Evaluation of the Production of Young Green Barley Plants Containing Functional Ingredients
}

\author{
Tianxiao Meng1, Chizuru Miura², Nobuto Irino ${ }^{2}$, Ryuichiro Kondo ${ }^{{ }^{*}}$ \\ ${ }^{1}$ Faculty of Agriculture, Kyushu University, Fukuoka, Japan \\ ${ }^{2}$ Asahi Ryokuken Co., Ltd., Fukuoka, Japan \\ Email: ${ }^{*}$ ryukondo@agr.kyushu-u.ac.jp
}

Received 13 January 2015; accepted 7 February 2015; published 10 February 2015

Copyright (C) 2015 by authors and Scientific Research Publishing Inc.

This work is licensed under the Creative Commons Attribution International License (CC BY). http://creativecommons. org/licenses/by/4.0/

(c) (i) Open Access

\section{Abstract}

We conducted experiments to establish the growing conditions of hydroponic young green barley plants in which functional ingredients were applied and absorbed during the cultivation period. No studies have conducted experiments on functional ingredients applied during the cultivation of young green barley. In this study, glucosamine (GIcN) and collagen (Cgn) were used, both of which are widely known as functional ingredients and are in high market demand. In the GlcN application experiment, young green barley plants were cultivated with only liquid fertilizer during the early growing period for 9 days, and then the plants were cultivated in $0.25 \%$ GlcN-water solution for the following 3 days. The plants used in this experiment absorbed $0.60 \%$ of GlcN. Furthermore, an experiment was conducted to test plant absorption of collagen. Collagen absorption was evaluated using hydroxyproline (Hyp) as an indicator ingredient. Under control conditions, the Hyp content was $0.04 \%$ after 14 days of cultivation. Meanwhile, in the application experiment of Cgn derived from pigs (average molecular weight is 3000 ), plants were cultivated in $1 \%$ Cgn-water solution for 14 days. As a result, the Hyp content increased to $\mathbf{0 . 2 8 \%}$. Thus, this study clarifies, for the first time, that barley plants can absorb exogenous functional ingredients applied from the outside. The nutrient component contents in young green barley plants were measured. The amino acid and vitamin $C$ content in hydroponic young green barley significantly increased, as compared to those grown in organic soil. Furthermore, in $0.1 \%$ Cgn-water solution cultivation, glutamic acid and aspartic acid, both of which are a functional amino acids, increased approximately three folds as compared to the plant grown in organic soil under natural sunlight. Furthermore, $\mathrm{K}$ and $\mathrm{Na}$, which are inorganic ingredients in young green barley, were measured. The $\mathrm{K}$ content in the plants grown in $1 \%$ Cgn-water solution cultivation for 14 days decreased by $80 \%$ as compared with the control hydroponic plant grown with liquid fertilizer. It was inferred that the plant might be used as food for dialysis patients.

\footnotetext{
*Corresponding author.
}

How to cite this paper: Meng, T.X., Miura, C., Irino, N. and Kondo, R. (2015) Evaluation of the Production of Young Green Barley Plants Containing Functional Ingredients. American Journal of Plant Sciences, 6, 323-333. 
Keywords

Young Green Barley, Hydroponic, Glucosamine, Collagen, Kalium (K)

\section{Introduction}

In recent years, there has been a growing demand for highly functional and enriched vegetables from general consumers, which are used to prevent lifestyle-related diseases that are associated with an aging society. The majority of studies on the production of useful materials that originate in organisms, but are later incorporated into plants via genetic modification, have focused on the research and development of medicines. For instance, studies have targeted medicines linked to vaccine generation and antibody production, but it has been quite difficult to produce such pharmaceutical products [1]-[4].

Meanwhile, regarding the cultivation of general vegetables and flowers, cost reduction strategies have been developed through the innovation of light-emitting diode (LED) light sources, the establishment of cultivation systems using information technology (IT), and an increase in established plant factories. With such developments in cultivation technology, the research and development of vegetables with functional ingredients is advancing, and an increasing number of studies have reported the enhancement of functional ingredients possessed by plants as well as the addition of new functional ingredients to plants.

Furthermore, in cereal grains, it was reported that sprouting leads to an increase in the content of plant ingredients and enhances the associated functions [5]. Barley sprouts were originally used as feed for livestock, and research on sprouts as feed ingredients has been developed. Research suggests that inorganic ingredients in barley such as $\mathrm{Ca}, \mathrm{Fe}$, and $\mathrm{Zn}$ increased more during sprouting as compared to those in other cereals, and that the essential amino acid content increased by $70 \%$ from days 4 to 7 after seed germination [6]. Moreover, some studies have described methods that enhance the GABA (gamma-aminobutyric acid) content in plants, including a method of increasing the content in raw tea leaves [7] and a technique to develop the content by utilizing glutamine acid decarboxylase contained in rice embryos [8]. Our previous research reported a GABA enhancement method through the activation of glutamic acid decarboxylase in the glutamic acid contained in young green barley [9].

Meanwhile, research suggests a method of enriching the content of functional ingredients in vegetables through the application of exogenous materials, not by enhancing the content that the vegetables initially possessed. For example, there are reports about the application of ascorbic acid to butterhead lettuce [10], the production of vegetables with high Fe content in leaves [11], and the development of lettuce with high Ca content [12].

The health food industry in Japan, reflecting its aging society, has mainly introduced products with added ingredients such as collagen, glucosamine, and hyaluronic acid, which are all said to help improve age-related diseases. However, it is necessary to be mindful of the allergic responses to added ingredients, as many are high in animal protein. Therefore, this study attempted to produce hydroponic young green barley plants with high functional ingredient content, in which allergenic substances were avoided via the application of glucosamine and collagen during the growth of the plants.

In 2002, research and development of the cultivation of vegetables with low potassium (K) content, designed for dialysis patients, was initiated, and some studies have reported cultivation methods for low K spinach [13]. Dialysis patients can only consume fewer than 1500 - $2000 \mathrm{mg}$ of K per day [14], and this results in a situation where the ability to eat fresh vegetables is limited due to the high levels of $\mathrm{K}$ in vegetables. In addition, the patients must boil vegetables to elute $\mathrm{K}$ before eating. The biggest problem in producing low $\mathrm{K}$ content vegetables is that $\mathrm{K}$ is an essential nutrient for plant growth [13]. Ogawa et al. have suggested a technique for the production of low $\mathrm{K}$ content spinach designed for dialysis patients that adjusts the ratio of $\mathrm{K}$ in the applied fertilizer [13]. Moreover, an additional method of reducing K content and adjusting Na content in hydroponic leaf vegetables and tomatoes was also suggested [15]. We discovered an interesting phenomenon in our exogenous functional ingredient application test on young green barley plants in that the $\mathrm{K}$ content in the plants greatly decreased when a collagen-water solution was used as $\mathrm{N}$ source during the culture period. 


\section{Material and Methods}

\subsection{Plant Material and Growth Condition}

Two-rowed barley (Hordeum vulugare f. distichon) Nishinohoshi was harvested in 2014. Seeds of barley were surface-disinfected for 1 min with hypochlorous acid [(HClO), approximately $0.5 \%$ of active chlorine] and then rinsed several times with sterilized water.

\subsection{Hydroponic Culture Growth Condition}

Surface-disinfected seeds were sown in mesh tray that is set into the hydroponics container (L 25. $5 \mathrm{~cm} \times \mathrm{W} 12$. $5 \mathrm{~cm} \times \mathrm{H} 7 \mathrm{~cm}$, YAMATO PLASTIC, Japan) containing $900 \mathrm{~mL}$ of nutrient solution (Table 1) in a biotron growth chamber at $20^{\circ} \mathrm{C}$ for glucosamin absorption test or $15^{\circ} \mathrm{C}$ for collagen absorption test, $70 \% \pm 5 \%$ relative humidity under natural sun light with a day/night. Nutrient solutions were renewed once a day.

\subsection{Organic Fertilizers Culture Growth Condition for Comparison of Nutritional Composition}

Seed were sown in planters $\left(41 \mathrm{~cm} \times 20 \mathrm{~cm}\right.$, soil area $\left.820 \mathrm{~cm}^{2}\right)$ containing organic fertilizers (SHOEI, Miyazaki, Japan), grown in two different biotron at temperature of $15^{\circ} \mathrm{C}$ and $20^{\circ} \mathrm{C}, 70 \%$ relative humidity.

Table 1. Hydroponic culture conditions of young green barley.

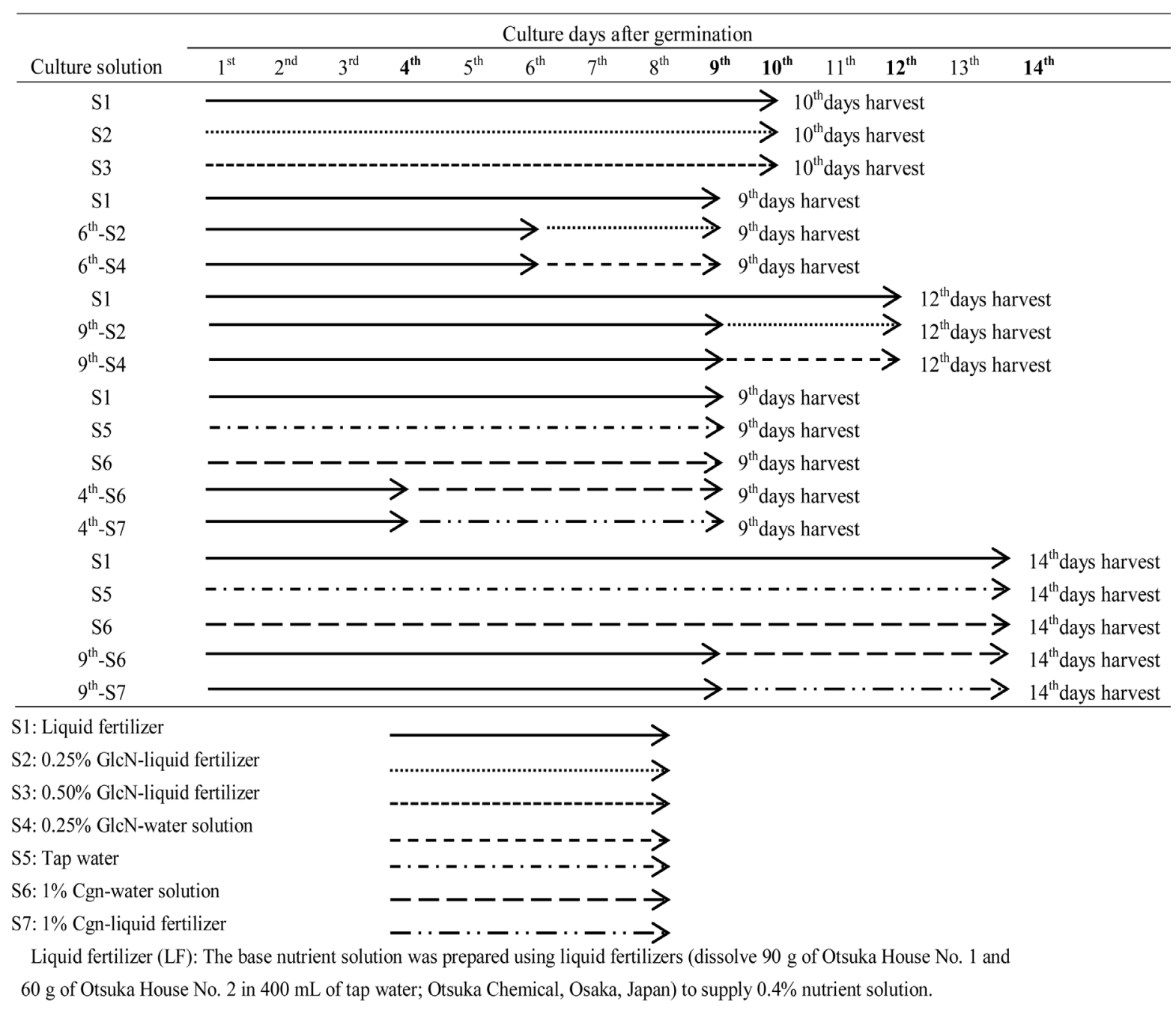




\subsection{Determination of Glucosamine and Hydroxyproline}

\subsubsection{Determination of Glucosamine}

Zero point onegram of sample was homogenized in $10 \mathrm{~mL}$ of $6 \mathrm{~mol} / \mathrm{L}$ hydrochloric acid, and the mixture was allowed to stand for $16 \mathrm{~h}$ at $100^{\circ} \mathrm{C}$. Evaporation of liquid mixture, obtain dry products, it dissolves in water and neutralization, and transferred into a $20 \mathrm{~mL}$ volumetric flask, adding water to volume than filtered. The supernatants were analyzed using the DX 500 HPLC System (Nippon Dionex K. K) equipped with a Dionex CarboPac PA1 $(4.0 \mathrm{~mm} \times 250 \mathrm{~mm})$ maintained at $32^{\circ} \mathrm{C}$. The mobile phase consisted of $0.05 \mathrm{~mol} / \mathrm{L}$ sodium hydroxide solution at a flow rate of $1.0 \mathrm{~mL} / \mathrm{min}$.

\subsubsection{Determination of Hydroxyproline}

As an oxidative reaction, one gram of sample was mixed with $20 \mathrm{~mL}$ of $20 \%$ hydrochloric acid (content in $0.04 \%$ 2-mercaptoethanol), and the mixture was allowed to stand for $24 \mathrm{~h}$ at $100^{\circ} \mathrm{C}$. The mixture solution, bring the final volume up to $100 \mathrm{~mL}$ by adding water. Than take $10 \mathrm{~mL}$ of solution (pH 2.2) dilute to $10 \mathrm{~mL}$ with sodium citrate buffer ( $\mathrm{pH}$ 2.2) as a test sample. The supernatants were analyzed using JLC-500/V AminoTac ${ }^{\mathrm{TM}}$ Amino Acid Analyzer (JEOL Ltd., Japan) equipped with a LCR-6 $(4.0 \mathrm{~mm} \times 120 \mathrm{~mm})$ column. The mobile phase was sodium citrate buffer (H-01-H-04, JEOL Ltd., Japan) at a flow rate of $0.42 \mathrm{~mL} / \mathrm{min}$ and the reaction solution (JEOL for ninhydrin coloring solution kit-II, Wako Pure Chemical Industries, Ltd., Japan) at a flow rate of $0.22 \mathrm{~mL} / \mathrm{min}$.

\subsection{Determination of Amino Acid Composition and Vitamin $\mathrm{C}$ and $\mathrm{E}$}

\subsubsection{Determination of Amino Acid Composition}

Amino acid (except for tryptophan) in the young green barley were determined by automatic amino acid analyzer JLC-500/V (JEOL Ltd., Japan), and tryptophan in the young green barley was measured by LC-20AD liquid chromatography unit (Shimadzu Ltd., Japan).

\subsubsection{Determination of Vitamin C and E}

Determination of vitamin C: Two to six grams of young green barley was homogenized in $50 \mathrm{~mL}$ of $5 \%$ metaphosphoric acid and centrifuged. Onemillilitre of extract was mixed with $1 \mathrm{~mL}$ of 5\% metaphosphoric acid, 200 $\mu \mathrm{L}$ of $0.2 \%$ 2,6-dichlorophenol-indophenol and $2 \mathrm{~mL}$ of $2 \%$ thiourea- $5 \%$ metaphosphoric solution. As an oxidative reaction $0.5 \mathrm{~mL}$ of $2 \%$ 2,4-dinitrophenyl-hydrazine $4.5 \mathrm{~mol} / \mathrm{L}$ sulfuric acid solution was added, and the mixture was allowed to stand for 16 hours at $38^{\circ} \mathrm{C}-42^{\circ} \mathrm{C}$. Then, $3 \mathrm{~mL}$ of ethyl acetate was added, and the mixture was shaken for about $60 \mathrm{~min}$. The supernatants were analyzed using the LC-20AT (Shimadzu Co., Ltd.) system equipped with a Senshupak Silica-1100-N column (Senshu Scientific Co., Ltd.) maintained at $35^{\circ} \mathrm{C}$. Extract was eluted in the mobile phase (ethyl acetate/hexane/acetic acid/water $=60 / 40 / 5 / 0.05$ ) at a flow rate of 1.5 $\mathrm{mL} / \mathrm{min}$. The absorbance of the eluent was measured at $495 \mathrm{~nm}$.

Determination of vitamin E: Young green barley was extracted using $0.3 \mathrm{~g}$ pyrogallol, $2 \mathrm{~mL}$ of $10 \mathrm{~g} / \mathrm{L}$ sodium chloride solution, and $10 \mathrm{~mL}$ of ethanol (approximately $1-2.5 \mathrm{~g}$ of sample/12 mL of solvent) and $2 \mathrm{~mL}$ of 600 $\mathrm{g} / \mathrm{L}$ potassium hydroxide. The mixture was boiled and then refluxed for $30 \mathrm{~min}$ at $70^{\circ} \mathrm{C}$. Next, the mixture was extracted in $20 \mathrm{~mL}$ of $10 \mathrm{~g} / \mathrm{L}$ sodium chloride solution, then $14 \mathrm{~mL}$ of hexane/ isopropanol/ethyl acetate (9/1.5/1) was added, and the mixture was centrifuged ( $5 \mathrm{~min}, 1500 \mathrm{rpm}$ ) three times and filtrated through a $0.45-\mu \mathrm{M}$ PTFE membrane syringe filter. The liquid chromatography LC-20AT system, equipped with an RF-10A fluorescence detector (Shimadzu Co., Ltd., Japan) was used for analysis. The peak was detected using an excitation wavelength of $298 \mathrm{~nm}$ and an emission wavelength of $325 \mathrm{~nm}$. The mobile phase was hexane/isopropanol/acetic acid (1000/6/5 with butylated hydroxytoluene), and the flow rate was $1.5 \mathrm{~mL} / \mathrm{min}$.

\section{Results}

\subsection{Production of Young Green Barley Containing GlcN}

\subsubsection{Growth of Young Green Barley in GIcN-Water Solution}

In a hydroponic experiment using water and liquid fertilizer, we conducted a growth test in GlcN-water solution with either $0.25 \%$ or $0.50 \%$ GlcN content, and the plants grown in $0.50 \%$ GlcN-water solution withered and died. Plant growth in $0.25 \%$ GlcN-water solution was largely inhibited as compared to that of the control plant 
that was exposed to liquid fertilizer, and the height and weight of the plants was inhibited to $72 \%$ and $57 \%$ on day 10 following germination, respectively (Table 2). As poor plant growth was observed when GlcN was applied during germination, plants were cultivated with only liquid fertilizer during the first 6 days during the 9-day growth period, and a growth test was conducted on plants exposed to $0.25 \%$ GlcN-water solution during the final 3 days. The plant growth during the final 3 days was examined by comparing plants grown in two different solution media: a water base with added GlcN solution and a liquid fertilizer base with added GlcN solution. Plant growth in both GlcN-water solution and GlcN-liquid fertilizer solution recovered up to $80 \%$ of the growth of those cultivated with the control liquid fertilizer solution (Table 2). Furthermore, a longer growing period was set, and plants were cultivated during a 12-day growing period. During this longer growth period, liquid fertilizer was applied for 9 days after germination, and then GlcN was added for the following 3 days. As a result, both the plant height and weight increases were found to be consistent with that of controls grown in liquid fertilizer (Table 2).

\subsubsection{GlcN Content in Young Green Barley}

GlcN was not detected in the control plants grown only in liquid fertilizer for 12 days. The GlcN content was $0.60 \%$ in the young green barley plants grown only in liquid fertilizer for 9 days and then in $0.25 \%$ GlcN-water solution for the following 3 days. However, the content was $0.20 \%$ in the plants grown in liquid fertilizer for 9 days and then in $0.25 \%$ GlcN liquid fertilizer solution for the following 3 days. It became clear that GlcN accumulated in the stems and leaves of young green barley without inhibiting plant growth under conditions where

Table 2. Effects of GlcN and Cgn-liquid fertilizers on the growth of young green barley.

\begin{tabular}{|c|c|c|c|c|c|c|c|c|}
\hline \multirow{2}{*}{$\begin{array}{l}\text { Culture } \\
\text { solution }\end{array}$} & \multicolumn{2}{|c|}{9 days after germination } & \multicolumn{2}{|c|}{10 days after germination } & \multicolumn{2}{|c|}{12 days after germination } & \multicolumn{2}{|c|}{14 days after germination } \\
\hline & $\begin{array}{l}\text { Height } \\
(\mathrm{cm})\end{array}$ & $\begin{array}{c}\text { Fresh weight } \\
\text { (g) }\end{array}$ & $\begin{array}{l}\text { Height } \\
(\mathrm{cm})\end{array}$ & $\begin{array}{c}\text { Fresh weight } \\
\text { (g) }\end{array}$ & $\begin{array}{l}\text { Height } \\
(\mathrm{cm})\end{array}$ & $\begin{array}{c}\text { Fresh weight } \\
\text { (g) }\end{array}$ & $\begin{array}{l}\text { Height } \\
\text { (cm) }\end{array}$ & $\begin{array}{c}\text { Fresh weight } \\
\text { (g) }\end{array}$ \\
\hline S1 & & & $49.4 \pm 3.0$ & $0.44 \pm 0.05$ & & & & \\
\hline S2 & & & $35.5 \pm 1.6$ & $0.25 \pm 0.02$ & & & & \\
\hline S3 & & & $18.9 \pm 1.7$ & $0.13 \pm 0.02$ & & & & \\
\hline S1 & $43.6 \pm 1.6$ & $0.35 \pm 0.03$ & & & & & & \\
\hline $6^{\text {th }}-\mathrm{S} 2$ & $38.1 \pm 1.9$ & $0.26 \pm 0.03$ & & & & & & \\
\hline $6^{\text {th }}-\mathrm{S} 4$ & $38.4 \pm 2.1$ & $0.28 \pm 0.02$ & & & & & & \\
\hline S1 & & & & & $51.8 \pm 4.8$ & $0.41 \pm 0.04$ & & \\
\hline $9^{\text {th }}-\mathrm{S} 2$ & & & & & $51.5 \pm 5.0$ & $0.40 \pm 0.04$ & & \\
\hline $9^{\text {th }}-\mathrm{S} 4$ & & & & & $52.9 \pm 5.2$ & $0.40 \pm 0.04$ & & \\
\hline S1 & $32.7 \pm 1.4$ & $0.29 \pm 0.03$ & & & & & & \\
\hline S5 & $23.8 \pm 1.4$ & $0.15 \pm 0.02$ & & & & & & \\
\hline S6 & $27.6 \pm 2.0$ & $0.17 \pm 0.02$ & & & & & & \\
\hline $4^{\text {th }}-\mathrm{S} 6$ & $30.3 \pm 2.0$ & $0.23 \pm 0.03$ & & & & & & \\
\hline $4^{\text {th }}-\mathrm{S} 7$ & $30.8 \pm 1.5$ & $0.25 \pm 0.02$ & & & & & & \\
\hline S1 & & & & & & & $50.7 \pm 3.9$ & $0.39 \pm 0.05$ \\
\hline S5 & & & & & & & $29.9 \pm 1.2$ & $0.19 \pm 0.02$ \\
\hline S6 & & & & & & & $35.7 \pm 1.2$ & $0.22 \pm 0.01$ \\
\hline $9^{\text {th }}-\mathrm{S} 6$ & & & & & & & $49.1 \pm 4.3$ & $0.36 \pm 0.03$ \\
\hline $9^{\text {th }}-S 7$ & & & & & & & $49.2 \pm 3.2$ & $0.36 \pm 0.02$ \\
\hline
\end{tabular}

S1: Liquid fertilizer; S2: 0.25\% GlcN-liquid fertilizer; S3: 0.50\% GlcN-liquid fertilizer; S4: 0.25\% GlcN-water solution; S5: Tap water; S6: $1 \%$ Cgn-water solution; S7: 1\% Cgn-liquid fertilizer. 
plants were cultivated only in liquid fertilizer for 9 days, and then for 3 days in the GlcN added solution.

\subsection{Production of Young Green Barley Containing Cgn}

\subsubsection{Examination of Growth Conditions under Cgn Application}

In hydroponic cultivation with water and liquid fertilizer, a 9-day cultivation test was conducted in $1 \%$ Cgn content solution. We cultivated young green barley plants under the following five conditions: (1) control with only liquid fertilizer, (2) control with only water, (3) 1\% Cgn content water solution, (4) only liquid fertilizer for 4 days and then $1 \%$ Cgn content water solution for the following 5 days, (5) only liquid fertilizer for 4 days and then in $1 \%$ Cgn content liquid fertilizer solution for the following 5 days (Table 1 ).

The plant height and weight increase of young green barley in the 9-day cultivation test are indicated as follows: (1) > (5) > (4) > (3) > (2). Furthermore, collagen addition during the latter 5 days induced slight growth inhibition as compared to the plant growth in (1) control with only liquid fertilizer, with $86 \%$ and $79 \%$ in the fresh weight of (5) and (4), respectively (Table 2). When the culture period was extended to 14 days to avoid growth inhibition, the weight increase and plant height were examined under two culture conditions. One was only liquid fertilizer for 9 days followed by $1 \%$ Cgn content-water solution for 5 days, and the other was only liquid fertilizer for 9 days and then 1\% Cgn content-liquid fertilizer solution for 5 days. The results indicate that the weight increase and plant height were $92 \%$ and $97 \%$ of those under control culture conditions, respectively; thus, indicating that growth inhibition was avoided (Table 2).

\subsubsection{The Hydroxyproline (Hyp) Content in Young Green Barley}

As an index of the Cgn content, the hydroxyproline (Hyp) amount was measured [14]. The Hyp content in young green barley plants grown for 9 days is shown in Table 3. The Hyp content was approximately 50 $\mathrm{mg} / 100 \mathrm{~g}$ dry weight in liquid fertilizer and water cultivation, both of which are controls in which Cgn was not added. Meanwhile, the content increased to $165 \mathrm{mg}$ in 1\% Cgn content-water solution cultures. In addition, 120 $\mathrm{mg}$ in the Hyp content was observed in the plants grown in 1\% Cgn content-water solution for the latter 5 days. The Hyp content data during the 14-day growing period are shown in Table 3. After cultivating in 1\% Cgn content-water solution for 14 days, the Hyp content was $284 \mathrm{mg}$. Moreover, the Hyp content was approximately 100 $\mathrm{mg}$ in plants grown under both of the two culture conditions. For instance, one was only in liquid fertilizer for 9 days and then in $1 \%$ Cgn content-water solution for 5 days, and the other was only in liquid fertilizer for 9 days and then in 1\% Cgn-content liquid fertilizer solution for 5 days; however, neither induced growth inhibition associated with plant height and weight increase. These results indicate that plants grew better in Cgn added media with water but not with liquid fertilizer, and that the Hyp content increased in proportion to the length of its application period.

\subsubsection{Comparison of Nutrient Components of Young Green Barley Containing Cgn}

We discovered that exogenous functional ingredients could be added during the cultivation period of young

Table 3. Hydroxyproline contents of young green barley under different liquid fertilizer conditions.

\begin{tabular}{ccc}
\hline \multirow{2}{*}{ Culture solution } & \multicolumn{2}{c}{ Hydroxyproline contents (mg/100g dry weight) } \\
\cline { 2 - 3 } S1 & 9 days after germination & 14 days after germination \\
S5 & 47 & 39 \\
S6 & 53 & - \\
S6 & 165 & 284 \\
$4^{\text {th }}-\mathrm{S} 6$ & - & - \\
$4^{\text {th }}-\mathrm{S} 6$ & 120 & 202 \\
$9^{\text {th }}-\mathrm{S} 6$ & - & 98 \\
$4^{\text {th }}-\mathrm{S} 7$ & - & 100 \\
$9^{\text {th }}-\mathrm{S} 7$ & - & -
\end{tabular}

S1: Liquid fertilizer; S5: Tap water; S6: $1 \%$ Cgn-water solution; S7: 1\% Cgn-liquid fertilizer. 
green barley; however, it is not meaningful if that addition is accompanied by a large decrease in the basic nutrient components of the plant. Therefore, an organic soil cultivation test was conducted in planters set inside a biotron, and the results were compared to the analyzed amino acid content, vitamin C, and vitamin E data from the previous hydroponic cultivation tests. In hydroponic culture, we analyzed the nutrient components of young green barley plants grown only in liquid fertilizer for 14 days and those of plants cultivated only in liquid fertilizer for 4 days and then in 1\% Cgn-water solution for more 10 days. The total amino acid content of plants grown under these conditions was 1.46 times larger than those grown under control conditions (Table 4). Glutamic acid and aspartic acid increased approximately 2.5 folds when Cgn was applied during the cultivation period. After Cgn application, vitamin C increased slightly and vitamin E increased approximately 1.5 folds, relative to the control (Table 5). Furthermore, the amino acid and vitamin $C$ content in young green barley plants grown in planter soil under natural sunlight inside the biotron were less than that of hydroponic plants grown under natural light (Table 4 and Table 5).

Table 4. Amino acid composition of young green barley grown under different culture conditions.

\begin{tabular}{|c|c|c|c|c|}
\hline & \multicolumn{4}{|c|}{ Amino acid contents (g/100g dry weight) } \\
\hline & \multicolumn{2}{|c|}{ Organic soil culture } & \multicolumn{2}{|c|}{ Hydroponic culture } \\
\hline & Natural sun light & Artificial sun light & $1 \%$ collagen water solution & Liquid fertilizer \\
\hline Arginine & 1.40 & 0.89 & 1.61 & 1.35 \\
\hline Lysine & 1.54 & 1.04 & 1.71 & 1.53 \\
\hline Histidine & 0.54 & 0.39 & 0.61 & 0.55 \\
\hline Phenylalanine & 1.28 & 0.90 & 1.29 & 1.24 \\
\hline Tyrosine & 0.91 & 0.61 & 0.91 & 0.83 \\
\hline Leucine & 1.98 & 1.38 & 2.02 & 1.93 \\
\hline Isoleucine & 1.01 & 0.69 & 1.06 & 1.00 \\
\hline Methionine & 0.49 & 0.31 & 0.52 & 0.47 \\
\hline Valine & 1.39 & 0.95 & 1.57 & 1.37 \\
\hline Alanine & 1.64 & 1.10 & 2.01 & 1.71 \\
\hline Glycine & 1.32 & 0.93 & 1.50 & 1.39 \\
\hline Proline & 1.17 & 0.81 & 1.18 & 1.12 \\
\hline Glutamic acid & 2.62 & 1.66 & 6.99 & 2.93 \\
\hline Serine & 1.10 & 0.73 & 1.39 & 1.05 \\
\hline Threonine & 1.16 & 0.79 & 1.27 & 1.12 \\
\hline Aspartic acid & 2.27 & 1.55 & 7.30 & 2.80 \\
\hline Tryptophan & 0.58 & 0.36 & 0.51 & 0.48 \\
\hline Cystine & 0.32 & 0.20 & 0.40 & 0.32 \\
\hline Total amino acid & 22.72 & 15.29 & 33.85 & 23.19 \\
\hline
\end{tabular}

Table 5. Vitamin C (ascorbic acid) and E (tocopherol) contents of young green barley grown under different culture conditions.

\begin{tabular}{ccccc}
\hline & \multicolumn{4}{c}{ Vitamin contents (mg/100g dry weight) } \\
\cline { 2 - 5 } & \multicolumn{2}{c}{ Organic soil culture } & Hydroponic culture \\
\cline { 2 - 6 } & Natural sun light & Artificial sun light & 1\% collagen water solution & Liquid fertilizer \\
\hline Total ascorbic acid & 367.5 & 262.5 & 450.0 & 434.0 \\
$\alpha$-tocopherols & 12.8 & 27.5 & 20.2 & 12.1 \\
$\gamma$-tocopherols & 3.4 & 5.0 & 4.6 & 3.0 \\
\hline
\end{tabular}

$\beta$ and $\delta$-tocopherols were not detedted. 


\subsection{K and Na Content in Young Green Barley}

The K and Na content in young green barley plants grown for 9 days in only liquid fertilizer or only in water are shown in Table 6. The K content of the control plants grown only in liquid fertilizer was $5.9 \mathrm{~g} / 100 \mathrm{~g}$, while the content in the control plants grown only in water was $1.7 \mathrm{~g} / 100 \mathrm{~g}$, indicating a $29 \%$ decrease. Furthermore, the Na content was supplementary to the decrease in the K amount. In the cultivation in only $1 \%$ Cgn-water solution, the $\mathrm{K}$ content decreased further to the level of $1.2 \mathrm{~g} / 100 \mathrm{~g}$, indicating a $20 \%$ decrease in plants grown in liquid fertilizer control conditions. However, when plants were grown in only liquid fertilizer for the first 4 days and then in 1\% Cgn-water solution for the latter 5 days, a slight increase was observed in the K content (Table 6). The $\mathrm{K}$ content was $1.2 \mathrm{~g} / 100 \mathrm{~g}$ in the plants grown in $1 \% \mathrm{Cgn}$-water solution for 14 days. The amount of $\mathrm{K}$ in the young green barley plants grown in liquid fertilizer for 3 days and then in $1 \%$ Cgn-water solution for 10 days increased to $2.40 \mathrm{~g}$, but it was only approximately $40 \%$ of the content found in plants grown in the liquid fertilizer control. In Cgn-added cultivation, the amount of Na tended to increase along with a decrease in the K content, but the Na increase was limited relative to the decreased $\mathrm{K}$ amount.

\section{Discussion}

The component profiling of young green barley has already been developed, and various studies have been conducted on the ingredients [16]-[18]. Our previous research also reported that different light sources irradiated during the growing period affected plant components [19]. Young green barley plants grow as fast as $20 \mathrm{~cm}$ in 10 days after germination, and the plant sprouts are a promising material for fresh juice next to bean sprouts. In the research regarding the ingredients of grain sprouts, Trubey et al. examined hydroponic oat sprouts [20], and studies on barley and wheat sprouts have focused on plant cultivating conditions for cow feed and ingredients that can induce an increase in milk and quality meat production [21]. Our previous research clarified that cultivation under LED irradiation increased amino acids in young green barley plants [19], and we established a method of increasing the GABA content that originally existed in young green barley [9]. Thus, it was suggested that LED hydroponic cultivation might be one of the effective cultivation methods for growing young green barley in the future.

In the present study, we examined the application and plant absorption of glucosamine (GlcN) and collagen (Cgn), both of which are functional ingredients contained in young green barley plants in small amounts. An experiment was initially conducted on the plant absorption of glucosamine $(\mathrm{GlcN})$, which is a low-molecularweight functional ingredient. In the 13-day cultivation experiment with a liquid fertilizer control, no peak of the GlcNcontent was observed; thus, it was understood that GlcN was not synthesized in vivo. Next, when young green barley plants were grown only in liquid fertilizer for 9 days and then in $0.25 \%$ GlcN-liquid fertilizer medium for the following 3 days, it was observed that $0.2 \mathrm{~g} / 100 \mathrm{~g}$ of GlcN dry weight was absorbed into plants. Meanwhile, when grown in $0.25 \% \mathrm{GlcN}$-water medium for the latter 3 days, it was found that $0.6 \mathrm{~g} / 100 \mathrm{~g}$ of GlcNdry weight was absorbed into plants. The present study is the first research reporting the absorption of exogenous functional ingredients from young green barley roots.

Next, we examined the plant absorption of Cgn, a functional ingredient that is much higher in molecular weight than GlcN. Inoue et al. reported in their study on lettuce that only those exogenous functional ingredients that were less than 1000 in molecular weight could be absorbed through the roots [22]. In the present study, we used low-molecular-weight Cgn (average molecular weight of 3000) derived from pigs, which was understood

Table 6. K and Na contents of young green barley under different culture conditions.

\begin{tabular}{|c|c|c|c|}
\hline \multirow{2}{*}{ Culture solution } & \multicolumn{2}{|c|}{$\mathrm{K}$ contents (mg/100g dry weight) } & \multirow{2}{*}{$\begin{array}{c}\text { Na contents } \\
\text { (mg/100g dry weight }\end{array}$} \\
\hline & 9 days after germination & 14 days after germination & \\
\hline S1 & 5940 & - & 111 \\
\hline S5 & 1690 & - & 945 \\
\hline S6 & 1230 & 1220 & - \\
\hline $4^{\text {th }}-\mathrm{S} 6$ & 3820 & 2400 & - \\
\hline
\end{tabular}

S1: Liquid fertilizer; S5: Tap water; S6: 1\% Cgn-water solution. 
to be close to the composition of human Cgn. Recent studies have shown that not all mammalian Cgn is broken down and absorbed as amino acids, but are instead absorbed and exist in the blood as dimers and oligomers [23]. Furthermore, research suggests that hydroxyproline, which is regarded as an index substance for Cgn absorption in mammals, acts as an extension for plant cell wall proteins and is involved in plant vegetative growth, differentiation, and cell wall formation [24]. Since Cgn has an average molecular weight of 3000, which is quite high for root absorption, we examined Cgn-added cultivation conditions and measured the Hyp content. It was observed that the Hyp content increased in plants grown under the 9-day cultivation conditions in 1\% Cgn-water solution. The Hyp content was at the maximum level of $284 \mathrm{mg} / 100 \mathrm{~g}$ in the 14-day cultivation in 1\% Cgn-water solution, and the content was approximately 7 times higher than plants grown under control conditions (Table 3). However, it was found that growth inhibition for young green barley was severe under this cultivation condition (Table 2). In the 9-day cultivation in only water or liquid fertilizer, the Hyp content was $53 \mathrm{mg} / 100 \mathrm{~g}$ and 47 $\mathrm{mg} / 100 \mathrm{~g}$, respectively (Table 3). The Hyp content was $39 \mathrm{mg} / 100 \mathrm{~g}$ in the 14-day cultivation in liquid fertilizer (Table 3). Therefore, the original content of Hyp in young green barley was thought to be approximately 40 - 55 $\mathrm{mg} / 100 \mathrm{~g}$. It was inferred that this Hyp content was the amount of Hyp contained in substances such as extensins that function in plant cell walls [24].

The Hyp content was $109 \mathrm{mg} / 100 \mathrm{~g}$ on average in the 5-day cultivation in $1 \%$ Cgn-water solution, 165 $\mathrm{mg} / 100 \mathrm{~g}$ in the 9 -day cultivation, and $284 \mathrm{mg} / 100 \mathrm{~g}$ in the 14-day cultivation (Table 3). Therefore, it was hypothesized that young green barley absorbed Cgn, as the Hyp content increased in proportion to Cgn added during the cultivation period. In addition, in the case of Cgn-added cultivation utilizing liquid fertilizer, the Hyp content was lower than in plants grown without liquid fertilizer, and an increase in the Hyp content in proportion to the period was not observed (data not shown). Therefore, this is inferred to be due to the preferentially utilization of liquid fertilizer by barley plants.

It is understood that Cgn in mammals is absorbed and exists in the form of dimers such as Pro-Hyp and HypGly, or in the form of oligopeptides such as Pro-Hyp-Glyn and Pro-Hyp-Hyp-Gly [24]. The present study is the first report on the absorption of Hyp by young green barley plants via the addition of $1 \%$ Cgn during the growing period. Further investigations are required to examine the molecular form of Cgn that is absorbed.

As young green barley is utilized widely as a functional ingredient material, it is not meaningful if nutrition components that originally exist in the plants decrease, even though the exogenous functional ingredients GlcN and Cgn are absorbed by plants. Therefore, we conducted an experiment to grow young green barley in organic soil planters set inside a biotron, as an original growing model of young green barley, and we subsequently compared the amino acid, vitamin C, and vitamin E contents of the plants grown in the biotron to those grown in 1\% Cgn nutrient medium conditions (Table 4 and Table 5). The amino acid content was approximately the same amount in soil cultivation under natural sunlight (NSL) and in liquid fertilizer cultivation (LF), and the vitamin C content in 1\% Cgn LF was approximately 18\% higher than that in plants grown in NSL. It was also found that $\alpha$ and $\gamma$-tocophrols related to vitamin $\mathrm{E}$ in plants grown in 1\% Cgn solution increased, as compared to NSL and LF.

Furthermore, the total amino acid content in plants grown in the 1\% Cgn solution was approximately $45 \%$ higher than that of plants grown in LF and NSL. Glutamic acid (Glu) and aspartic acid (Asp), in particular, weighed approximately 2.5 times more in comparison with controls grown in liquid fertilizer. This particular increase in the Glu and Asp contents did not reflect the amino acid composition of pig Cgnthat was originally applied. Thus, it was suggested that this unique increase in the two amino acids (Glu and Asp) might be due to an effect on the tricarboxylic acid (TCA) cycle made by $\mathrm{C}$ and $\mathrm{N}$ sources derived from Cgn. Glu and Asp have been used as functional amino acids, and this research suggests that young green barley with a new function might be produced.

As a food material for dialysis patients, there is a demand for the production of low $\mathrm{K}$ content vegetables. Research suggests that the $\mathrm{K}$ content in spinach decreased $80 \%$ by decreasing the $\mathrm{K}$ supply in water culture solution during the latter half of hydroponic cultivation [8]. When a limited amount of nitrate nitrogen was applied in the later period of cultivation to produce low $\mathrm{K}$ content lettuce or spinach, the $\mathrm{K}$ content in plants decreased drastically [13]. The K content of young green barley was measured from plants grown in a culture medium in which Cgn was added as an $\mathrm{N}$ source. The $\mathrm{K}$ content of plants grown in the 9-day cultivation with $1 \%$ Cgn water solution was $1.2 \mathrm{~g} / 100 \mathrm{~g}$ and that of plants grown in the 14-day cultivation with Cgn water solution was 1.2 $\mathrm{g} / 100 \mathrm{~g}$, both of which showed an $80 \%$ decrease as compared to the control with only liquid fertilizer. This result 
was consistent with that observed in spinach by Ogawa et al. [8]. In addition, the $\mathrm{K}$ content in plants grown in $1 \%$ Cgn-water solution from days 4 for 10 days decreased to the level of $2.40 \mathrm{~g} / 100 \mathrm{~g}$, which was a $60 \%$ decrease in comparison to the control conditions with only liquid fertilizer. It is understood that a decrease in the $\mathrm{K}$ content is accompanied by an increase in the Na content as a substitution effect [17]. The Na content in the 9-day cultivation with only water was 8.5 times greater than plants grown in the control cultivation with only liquid fertilizer. Furthermore, it was observed that the Na content increased as a substitution effect in the 14-day cultivation with $1 \%$ Cgn, corresponding to a decrease in the K content [17]. However, the increase in the Na content was only at about a half of that in plants grown in water only cultivation. Considering the fact that dialysis patients have restrictions on both $\mathrm{K}$ and Na intake, there is a possibility of lowering the $\mathrm{K}$ and Na contents in young green barley plants. Furthermore, it is necessary to examine in detail the conditions in which the K content decreases in plants grown in collagen-added culture medium, and to produce nutritious and functional young green barley plants that dialysis patients are able to eat.

\section{References}

[1] Daniell, H., Streatfield, S.J. and Wycoff, K. (2001) Medical Molecular Farming:Production of Antibodies, Biopharmaceuticals and Edible Vaccines in Plants. Trends in Plant Science, 6, 219-226.

[2] Walmsley, A.M. and Arntzen, C.J. (2003) Plant Cell Factories and Mucosal Vaccines. Current Opinion in Biotechnology, 14, 145-150.

[3] Horn, M.E., Woodard, S.L. and Howard, J.A. (2004) Plant Molecular Farming: System and Products. Plant Cell Reports, 22, 711-720.

[4] Akita, M. and Suzuki, T. (2010) Biological and Systems Engineered Approach for Highly Efficient and High-ValueAdded Production in Plant Factory System. Memoirs of the Faculty of Biology-Oriented Science and Technology of Kinki University, 26, 23-37.

[5] Chavan, J.K., Kadam, S.S. and Beuchat, L.R. (1989) Nutritional Improvement of Cereals by Sprouting. Critical Reviews in Food Science and Nutrition, 28, 401-437.

[6] Peer, D.J. and Leeson, S. (1985) Nutrient Content of Hydroponicaliy Sprouted Barley. Animal Food Science and Technology, 13, 191-202.

[7] Tsushida, T., Murai, T., Omori, M. and Okamoto, J. (1987) Production of New Type Tea Containing a High Level of y-Aminobutyric Acid. Nippon NogeikagakuKaishi, 61, 817-822. http://dx.doi.org/10.1271/nogeikagaku1924.61.817

[8] Saikusa, T., Horino, T. and Mori, Y. (1994) Accumulation of $\gamma$-Aminobutylic Acid (GABA) in the Rice Germ During Water Soaking. Bioscience Biotechnology Biochemistry, 58, 2291-2292.

[9] Koga, R., Tsubata, M., Ikeguchi, M., Takagaki, K., Irino, N. and Kondo, R. (2012) Enriched Production of $\gamma$-Aminobutyric Acid on Young Barley Leaves and Its Antihypertensive Effect in Spontaneously Hypertensive Rats. The Journal of Japan Mibyou System Association, 18, 11-16

[10] Inoue, K., Yokota, H. and Makita, K. (1994-1995) Introduction of Exogenous Sodium Ascorbate into Lettuce (Butter Head Type) Grown Hydroponically. Journal of the Japanese Society for Horticultural Science, 63, 779-785.

[11] Inoue, K., Tajima, K., Sanada, K. and Yokota, H. (1995) Production of Iron-Enriched Leaf Vegetables Using a Soaking Method. Japanese Society of Soil Science and Plant Nutrition, 66, 527-534.

[12] Inoue, K., Takayama, S. and Yokota, H. (1994) Production of Calcium-Enriched Lettuce (Lactuca sativa L.) Using a Soaking Method. Japanese Society of Soil Science and Plant Nutrition, 66, 381-387.

[13] Ogawa, A., Taguchi, S. and Kawashima, C. (2007) A Cultivation Method of Spinach with a Low Potassium Content for Patients on Dialysis (Quality and Processing). Japanese Journal of Crop Science, 76, 232-237. http://dx.doi.org/10.1626/jcs.76.232

[14] Ogawa, H. and Ono, M. (2005) Handbook of Dialysis. Third Edition, Igaku-Shoin Ltd., Tokyo, 75-83.

[15] Ogawa, A., Eguchi, T. and Toyofuku, K. (2012) Cultivation Methods for Leafy Vegetables and Tomatoes with Low Potassium Content for Dialysis Patients. Environmental Control in Biology, 50, 407-414. http://dx.doi.org/10.2525/ecb.50.407

[16] Federico, F., Zuzana, K., Rui, F.G., Patricia, V., Jose, A.P., Jaroslav, D., et al. (2009) Free Water-Soluble Phenolics Profiling in Barley (Hordeum vulgare L.). Journal of Agricultural and Food Chemistry, 57, 2405-2409. http://dx.doi.org/10.1021/jf8037727

[17] Norbaek, R., Aaboer, D.B., Bleeg, I.S., Christesen, B.T., Kondo, T. and Brandt, K. (2003) Flavone C-Glycoside, Phenolic Acid, and Nitrogen Contents in Leaves of Barley Subject to Organic Fertilization Treatments. Journal of Agricultural and Food Chemistry, 51, 809-813. http://dx.doi.org/10.1021/jf0258914 
[18] Benedet, J.A., Umeda, H. and Shibamoto, T. (2007) Antioxidant Activity of Flavonoids Isolated from Young Green Barley Leaves toward Biological Lipid Samples. Journal of Agricultural and Food Chemistry, 55, 5499-5504. http://dx.doi.org/10.1021/jf070543t

[19] Koga, R., Meng, T.X., Nakamura, E., Miura, C., Irino, N., Devkota, H.P., et al. (2013) The Effect of Photo-Irradiation on the Growth and Ingredient Composition of Young Green Barley (Hordeumvulgare L.) Agricultural Sciences, 4, 185-194. http://dx.doi.org/10.4236/as.2013.44027

[20] Trubey, C.R., Rhykerd, C.L., Noller, C.H., Ford, D.R. and George, J.R. (1969) Effect of Light, Culture Solution, and Growth Period on Growth and Chemical Composition of Hydroponically Produced Oat Seedlings. Agronomy Journal, 61, 663-665. http://dx.doi.org/10.2134/agronj1969.00021962006100050003x

[21] Dung, D.D., Godwin, I.R. and Nolan, J.V. (2010) Nutrient Content and in Sacco Digestibility of Barley Grain and Sprouted Barley. Journal of Animal and Veterinary Advances, 9, 2485-2492. http://dx.doi.org/10.3923/javaa.2010.2485.2492

[22] Inoue, K., Murase, H., Ogura, T., Nakahara, T. and Someya, T. (2004) Improvement of the Taste of Leaf Lettuce Grown Hydroponically by Soaking the Roots in Stevia rebaudiana Glycosides Solutions. Shokubutsu Kojo Gakkaishi, 16, 16-19.

[23] Koyama, Y. (2010) Functional Aspects of Collagen. Hikaku Kagaku, 56, 71-79.

[24] Iwai, K., Hasegawa, T., Taguchi, Y., Morimatsu, F., Sato, K., Nakamura, Y., et al. (2005) Identification of Food-Derived Collagen Peptides in Human Blood after Oral Ingestion of Gelatin Hydrolysates. Journal of Agricultural and Food Chemistry, 53, 6531-6536. http://dx.doi.org/10.1021/jf050206p 
Scientific Research Publishing (SCIRP) is one of the largest Open Access journal publishers. It is currently publishing more than 200 open access, online, peer-reviewed journals covering a wide range of academic disciplines. SCIRP serves the worldwide academic communities and contributes to the progress and application of science with its publication.

Other selected journals from SCIRP are listed as below. Submit your manuscript to us via either submit@scirp.org or Online Submission Portal.
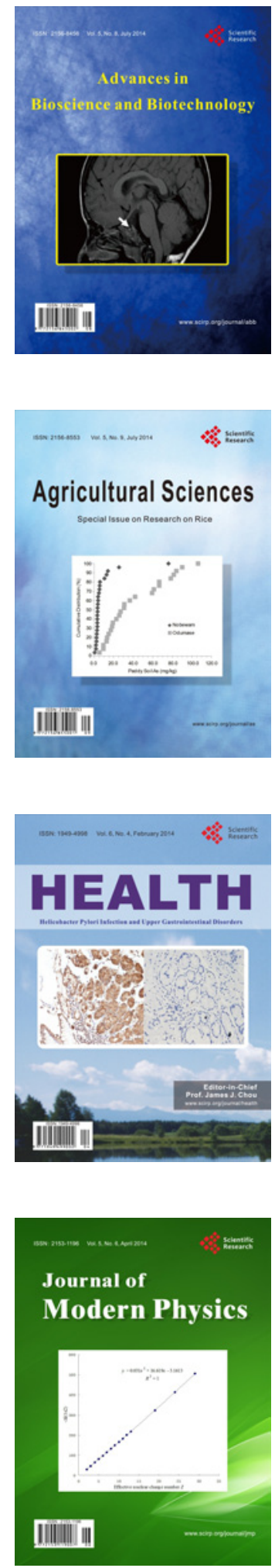
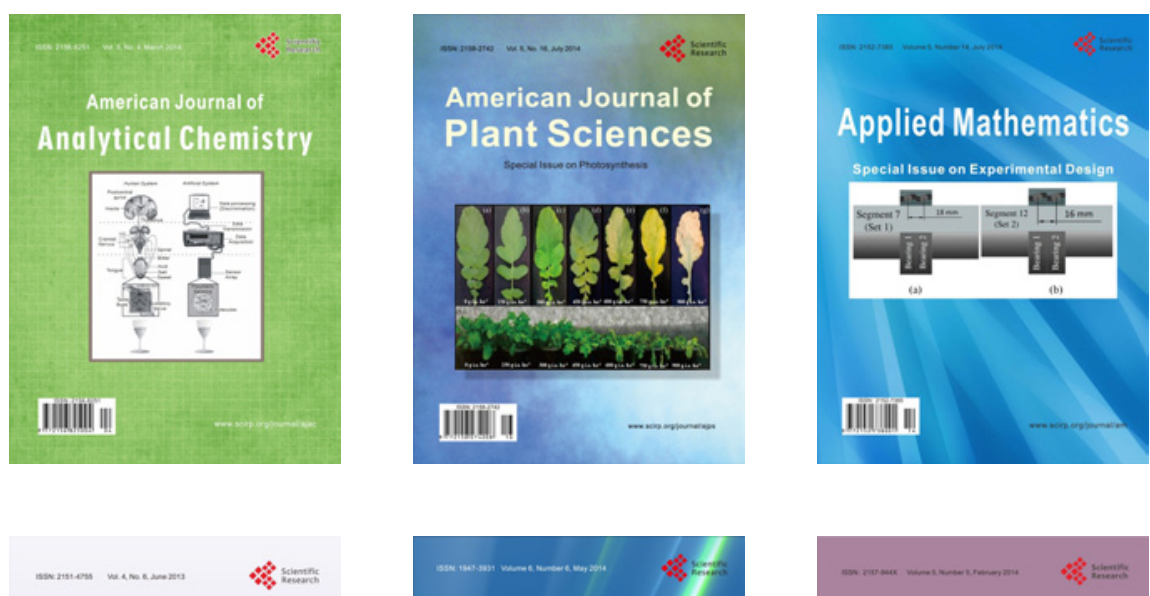

Creative Education
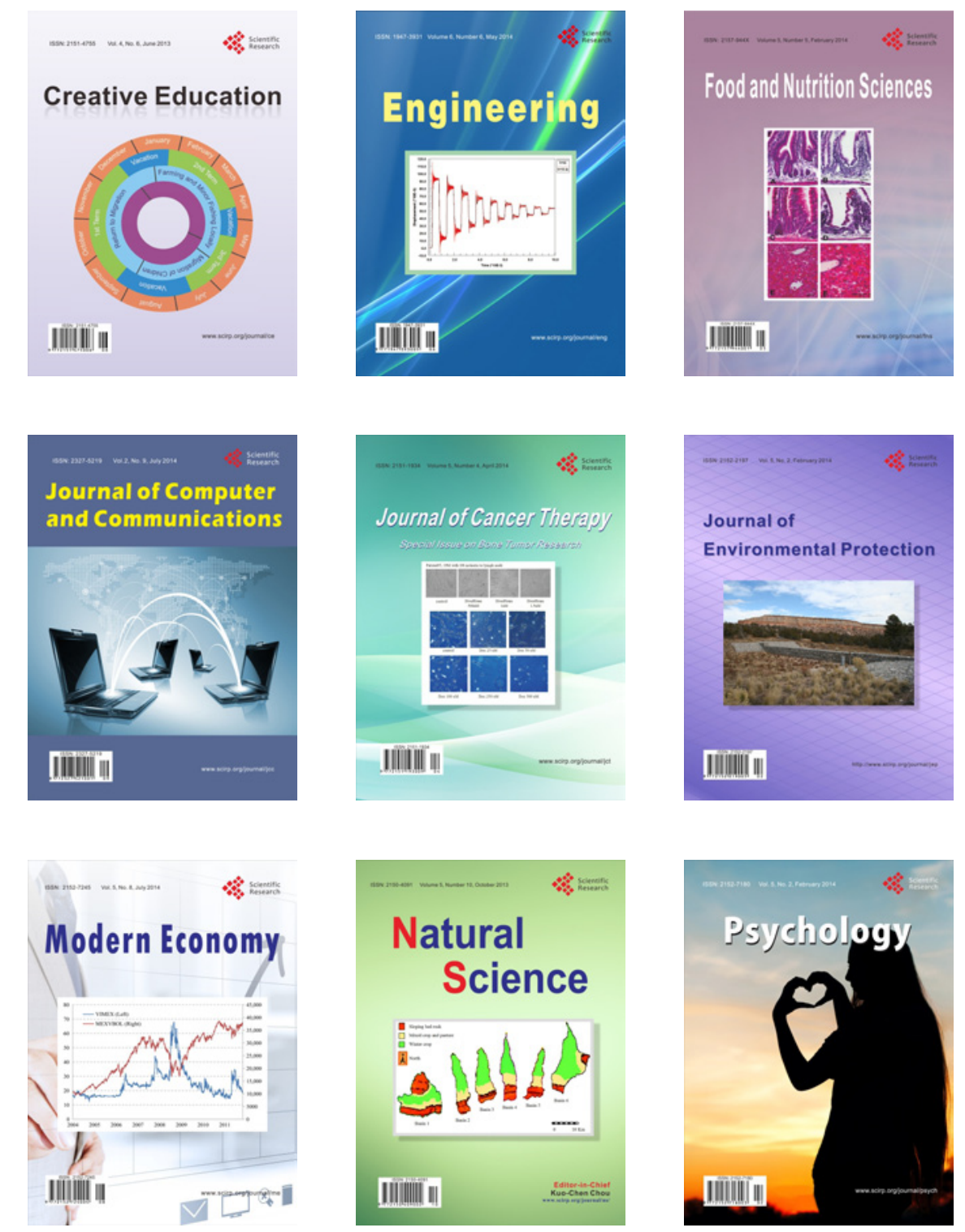